\title{
THE TREMATODE GENUS STEPHANOCHASMUS LOOSS IN THE GULF OF MEXICO.
}

\author{
BY HENRY S. PRATT, \\ Haverford College, Haverford, Pa.
}

(With Plate XIII.)

Two species of the genus Stephanochasmus have been found in the fishes examined for parasites at the station of the Carnegie Institution of Washington, situated on the island of Tortugas in the Gulf of Mexico. These are $S$. casus Linton and $S$. sentus Linton. The anatomy of these worms contains several novel and interesting features, and that of the first named will be described here in detail.

S. casus lives in the rectum of two common fishes, the gray snapper (Lutianus griseus) and the yellow tail (Ocyurus chrysurus), where it was found by both Linton (1910) and myself. The length of the eleven specimens in my collection ranges between $2 \mathrm{~mm}$. and $6 \mathrm{~mm}$. (Fig. 1). The body is soft and contractile and is consequently much broader at some times than at others. The breadth of the specimen figured, which is somewhat contracted, is $1 \mathrm{~mm}$. The breadth of a fully extended animal of the same length is about $0.7 \mathrm{~mm}$.

The living worm is usually deep red in colour, in consequence of the blood contained in the capacious intestine. In the various stages of contraction of the different individuals the organs may show a somewhat different arrangement. The testes and ovary, for instance, are pressed closely against one another when the body is much contracted (Fig. 2); but when it is extended these organs may be separated from one another by a considerable distance. The body is oval in cross section (Fig. 3). It is covered with the large spines characteristic of the genus, the number encircling the mouth being 36 , arranged in two rows (Fig. 1). These rows are not interrupted ventrally, as is the case in certain species of the genus. All the spines are very easily lost by maceration. 
The two suckers are of rather small size, the oral sucker (Fig. 1, 27), which is terminal in position, having a diameter, in the specimen figured, of $0.29 \mathrm{~mm}$. and the acetabulum (Fig. 1, 1) one of $0.49 \mathrm{~mm}$.

A pair of groups of pigment granules (Fig. 1, 32) is present in the dorsal body wall a short distance behind the pharynx, which, as Looss (1901) has shown, are the remains of the cercarian eyes and characterize most of the species of the genus. The granules composing each eye are very distinct and number from 20 to about 50. In much contracted specimens they are often crowded closely together or form a single mass, while in extended worms they are more or less separated from one another.

The mouth is cup-shaped, having a characteristic semi-circular outline, and opens into a long prepharynx (Fig. 1, 33) which in the specimen figured is $0.65 \mathrm{~mm}$. long. The hinder end forms a circular fold around the anterior end of the pharynx (17), which is a large piriform organ (31) $0.33 \mathrm{~mm}$. long and $0.22 \mathrm{~mm}$. thick.

An oesophagus (25) is present which is very short and wide, measuring $0.06 \mathrm{~mm}$. in length and $0.2 \mathrm{~mm}$. in width. It is really a part of the intestine inasmuch as it possesses its characteristic epithelium. The prepharynx, on the other hand, has the structure which usually characterizes the oesophagus of trematodes, as it possesses no epithelium and its lumen is bounded by a cuticula. It functions, in fact, as an oesophagus which has the pharynx at its hinder end instead of at its forward end.

The two intestinal trunks (20) pass at once transversely to the lateral areas of the body and then to the hinder end of it and are very wide, measuring $0.13 \mathrm{~mm}$. in diameter. Their epithelium consists of cells which vary much in height and shape in different individuals. In one of the four worms sectioned they were simple cubical or somewhat elongated cells throughout the greater part of the intestine which did not possess terminal filaments. In the other worms examined the shape of the epithelial cells of the intestine had apparently been. influenced by the food contents of the gut, and in a very interesting way. In the worm of which Figure 3 represents a cross section and Figure 4 a portion of the intestinal epithelium, the cells of this epithelium are, throughout a large part of the gut, considerably elongated, and with large nuclei, and from their free surfaces a fringe of long filiform protoplasmic processes extends into the lumen of the intestine. These processes are considerably longer than the cells themselves and four or five of them appear in a section extending from each cell (Fig. 4). 
They are all of approximately the same length and are strikingly regular in form and outline. They have thus the appearance of large cilia, and might easily be taken for such.

In other portions of the intestine of this worm, especially toward the hinder end of the body, and throughout the entire gut of the other two worms examined, the intestinal epithelial cells lack the regular form of those just described, although they also possess similar long protoplasmic filaments. Their free surfaces show a tendency to throw large blunt extensions into the lumen of the intestine, which have the appearance of the pseudopodia of rhizopods and give these surfaces a most irregular contour. From these extensions as well as from the free surface of the cells generally the cilia-like structures project still further into the lumen of the intestine. They are however relatively much shorter than the corresponding structures shown in Figure 4, being not more than a third or half the length of the cells from which they spring.

The structure of the intestinal epithelial cells here described has been observed by other authors in a variety of trematodes. It was first described by Sommer (1880) in Fasciola hepatica. The explanations given by him of the cause of this formation is that the free ends of these cells become amoeboid in order to more quickly and easily digest the blood which has been ingested and forms the food of the parasite. A similar explanation may also serve for the same structures in Stephanochasmus, as the capacious intestinal trunks are usually filled with blood. I could not, however, find a correlation, as Sommer does in the intestine of Fasciola, between the amount of blood in the intestine and the actual form and conditions of its epithelial cells. Sommer finds that where the intestine is empty its epithelial cells are relatively low and simple in contour; and only in those parts of the intestine which are well filled with blood are the epithelial cells high and irregular in contour. In Stephanochasmus casus the intestine as observed always contained blood whatever the condition of the epithelium.

The musculature of the long prepharynx is a powerful one, consisting of regular circular and longitudinal fibres. On the intestinal trunks, on the other hand, the musculature is apparently absent, or at least is exceedingly delicate: it could not be demonstrated with certainty.

The excretory pore (Fig. 1, 15) is at the hinder end of the broad papilla which forms the posterior end of the body. The excretory vesicle (16) consists of a long median trunk and two long paired trunks 
which pass forward to the region of the oral sucker. The median trunk is a wide canal which extends forward to the space between the ovary and the anterior testis, or in much contracted specimens to that between the ovary and the dorsal body-wall. In the region of the testes it lies, as a flattened tube about $0.1 \mathrm{~mm}$. wide, between these bodies and the dorsal body-wall. The two paired excretory canals are narrow tubes about $0.012 \mathrm{~mm}$. wide which pass forward, one to the right and the other to the left of the ovary along the ventral surface of the intestinal trunks to the extreme forward end of the body. In front of the acetabulum they are much convoluted.

The genital pore (Fig. 1, 18) is median in position, being situated in the narrow space between the acetabulum and the transverse intestinal trunks, and opens into a long cylindrical genital sinus (Fig. 2). This structure, in a worm in which the cirrus is not extended (Fig. 2) and the body is much contracted, measures about $0.13 \mathrm{~mm}$. in length : in a worm, however, the body of which is not contracted the genital sinus may be several times this length. It extends posteriorly either dorsal to the acetabulum or around one side of it.

The wall of the genital sinus (Fig. 5) is made up of a cuticula bounded by muscle fibres. The cuticula is continuous with that of the outer surface of the body, but is very different in structure. Instead of forming a smooth surface with large spines it is thickly set with short, perpendicular bristle-like projections (10) which arise near the outer surface of the cuticula and extend through it into the lumen of the sinus. These bristles may be compared with the spines of the outer cuticula. The muscle fibres consist of delicate circular fibres (4) surrounding the cuticula and powerful longitudinal fibres (22) which show a more or less rectangular cross section.

Joining the posterior end of the genital sinus are the cirrus sac (Figs. 1 and 2, 6) and the metraterm (24) which are extremely long, more or less cylindrical structures of about the same length, extending posteriorly to a point from a half to two-thirds the distance between the acetabulum and the ovary. Their actual position is dependent upon the condition of contraction of the body and whether the cirrus is extended or not. In Fig. 1, in which the cirrus (5) is extended and the body but little contracted, the cirrus sac is straight and not coiled and, not including the extended cirrus, about $1 \mathrm{~mm}$. long, reaching back of the acetabulum to a point about half-way between it and the ovary, while the metraterm (24) is but slightly coiled and extends a short distance back of the cirrus sac. In Fig. 2, on the other hand, in which 
the cirrus is not extended and the body is much contracted, the cirrus sac (6) and the metraterm (24) are seen to be of equal length and to extend more than two-thirds of the distance between the acetabulum and the ovary and to be thrown into a series of irregular coils.

The outer wall of the cirrus sac (Figs. 6 and 7, 46) is a musculature, the fibres of which form a sort of felt and do not fall into circular and longitudinal layers although they have a general circular direction. Within this wall is the characteristic vesicular parenchyma in which are embedded numerous parenchyma cells (30).

The hinder fifth of the cirrus sac has a somewhat greater diameter than the forward portion and contains the vesicula seminalis (Figs. 1 and 2,45 ). The remaining four-fifths forms a long slender tube which tapers slightly toward the forward end where it joins the genital sinus. Immediately anterior to the vesicula seminalis in this portion is the prostate region (35) which is short and contains the rather sparsely distributed prostate cells. The remainder of the lumen of the cirrus sac, constituting the anterior half or two-thirds, may be called the cirrus (Fig. 2, 5), of which only the anterior portion, however, can be extruded to form a functional penis (Fig. 1, 5).

The structure of the cirrus is similar to that of the genital sinus. Its lumen is bounded by a cuticula (Fig. 6, 8) which, like that of the genital sinus, is thickly set with perpendicular bristles. These extend through the entire thickness of the cuticula and into the lumen of the cirrus, giving it a very characteristic roughened surface.

It is only near its anterior end, however, that the cuticula has the character shown in Figure 6. A short distance back of the anterior end the perpendicular cuticular bristles become somewhat more delicate and embedded among them appear sparsely scattered spines of large size and peculiar construction. These spines are scattered at regular intervals and are very conspicuous objects (Fig. 7, 11). Each one consists of a bulbous base (Fig. 8, 3) which is embedded in the cuticula, lying near its outer surface, and a high cylindrical rim (13) which extends from the bulbous base to the inner surface of the cuticula. The total length of the bulbous base and the rim is thus equal to about the thickness of the cuticula of the cirrus. Extending now from the bulbous base through its cylindrical extension is a long slender spine which reaches beyond the general surface of the cuticula far into the lumen of the cirrus (Fig. 7, 11).

The structure of these peculiar spines is even more complicated than this description indicates. The bulbous base, which is spherical in 
shape, is made up of three regions: a thick basal disc (Fig. 8, 2), which lies near the outer surface of the cuticula, a thick-walled ring at the opposite side (36), through which the spine projects, and a middle portion which contains the broad inner end of the spine and appears lighter in colour than the other two portions. The spine is composed of a lighter coloured inner substance, and a darker periphery which is very thin and appears beaded (Fig. 8, 11).

These specialized spines are found throughout the entire extent of the cirrus (with the exception of the extreme anterior portion) and the prostate region. A short distance anterior to the vesicula seminalis they suddenly come to an end and the cuticula contains the cuticular bristles alone.

The musculature of the cirrus is not the same in all parts of it and enables us to divide the cirrus into two portions, the anterior, muscular, extrusile portion, which functions as the penis, and the posterior portion in which the muscles are weak. The musculature of the anterior portion is a continuation of that of the genital sinus and consists of rather delicate circular fibres (Fig. 6, 4) and a layer of powerful longitudinal fibres (22), which have a more or less rectangular cross section. The function of these strong longitudinal fibres in both cirrus and genital sinus is undoubtedly to thrust the cirrus out of the genital pore. They are the strongest towards the anterior end of the cirrus where they are a direct continuation of the longitudinal muscles of the genital sinus. Towards its posterior end they diminish in size and a short distance back of the acetabulum have the appearance shown in Fig. 7, 22. Still farther posteriorly both longitudinal and circular muscles become still less prominent and finally fade away altogether, or at least become difficult to demonstrate.

The function of the cuticular bristles and the cuticular spines of the cirrus is not easy to determine. In the extended cirrus they extend into the lumen with a general backward direction and would thus tend to check the flow of sperm towards the outside. Their function may be to prevent the too rapid emission of sperm.

The vesicula seminalis occupies the hinder portion of the cirrus sac (Figs. 1 and 2, 45). Its walls consist of a cuticula and muscle fibres. The cuticula is mostly plain and smooth and without the bristles or spines which characterize the cirrus. That of the anterior portion of the vesicula, however, shows transitional stages between the condition found in the cirrus and that of the vesicula.

The metraterm (24) has a structure which is essentially similar to 
that of the cirrus and the genital sinus. Its lumen is bounded by a cuticula (Figs. 6 and 7,8 ) which is a continuation of that of the genital sinus and similar to it in structure, containing the same cuticular bristles. These bristles appear more delicate, however, than those in the genital sinus or in the cirrus. Embedded in the cuticula are also large, specialized spines similar to those in the cirrus (12). They differ from those in the cirrus, however, in some details of their structure. The base is not bulbous as in the cirrus, but is more or less flattened (Fig. 9, 2) and the cylindrical rim (13) reaching to the inner surface of the cuticula is longer. The spine (12) which projects from the base through the rim is usually somewhat shorter than in the cirrus and does not show the beaded periphery which characterizes it. These spines are present in every part of the metraterm and occur with about the same frequency as in the cirrus. They are not quite so conspicuous, however, as they do not appear to have such thick walls. At any rate they do not take stains so vividly as do the spines in the cirrus.

The cin racter of the cuticula of the metraterm does not differ throughout its whole extent. The musculature is very delicate and consists of fibres which could not be separated into distinct layers.

The testes (Figs. 1 and 2, 40) are a pair of oval organs about $0 \cdot 3 \mathrm{~mm}$. long and half as thick which are situated one behind the other in the hinder half of the body. The posterior testis is usually somewhat longer than the anterior. When the body is much contracted the two testes are pressed closely together (Fig. 2); when it is much extended, however, they may be separated by a distance equal to about a quarter of their length. The vasa deferentia (Figs. 1 and 3,44 ) pass forward to the cirrus sac.

The ovary (Figs. 1, 2 and 3, 28) is a spherical body $0.23 \mathrm{~mm}$. in diameter which is situated directly in front of the anterior testis, often apparently somewhat at the left of the medial line. In a much contracted worm it may be closely pressed against the testis (Fig. 2, 28) and its shape changed to an oval. In worms whose body is fully extended it may be separated by $0.2 \mathrm{~mm}$. from the testis.

The oviduct (Fig. 10, 29) emerges from the antero-dorsal surface of the ovary slightly to the left of the medial line and passes dorsoventrally a short distance to the median area of the worm where it is joined by the median yolk duct (23) and the Laurer's canal (21). It then passes forwards and immediately expands to form the uterus. This structure is short and thick, lying between the ovary and the hinder end of the metraterm and the cirrus sac and bounded laterally 
'by the intestinal trunks. It is made up of two very distinct portions, the posterior or egg-forming portion (Figs. 1, 2 and 10, 42), which consists of two thick transverse folds and lies directly in front of the ovary, and the anterior or egg-storing portion (43) consisting of three or four folds which contain the eggs. The posterior or egg-forming portion represents the ootype of most distomes and is filled with sperm; it also contains a considerable number of the large eggs embedded in the sperm. This structure has been called the receptaculum seminis by Linton (1910). It is true that it contains sperm, but it is nevertheless not homologous to the receptaculum of other distomes inasmuch as it is a part of the uterus and contains also eggs. A receptaculum seminis in the ordinary sense is not present in any of the worms of this genus. An ootype is thus also absent in the form met with in other distomes. The condition of these organs in this worm may be considered a primitive one in that a specialized ootype has not developed from the posterior portion of the uterus. The eggs are of large size, measuring $0.06 \mathrm{~mm}$. by $0.045 \mathrm{~mm}$., and are few in number.

The yolk glands (Fig. 1, 47) are very voluminous, extending from the hinder margin of the acetabulum to the hinder end of the body, reaching thus farther forwards than in any member of the genus heretofore described. They completely occupy the lateral areas of the body, lying both dorsal and ventral to the wide intestinal trunks (Fig. 3, 47) and are bounded medially by the genital organs which occupy the medial areas of the body. The yolk glands consist of large follicles which are arranged in transverse rows extending from the periphery towards the centre of the body. The main transverse yolk duits (Fig. 10, 41) meet dorsal to the ovary (Fig. 2) and not between the ovary and the anterior testis as in all other members of the genus, and form a large yolk reservoir (Fig. 10,48) from which a long median yolk duct (23) passes antero-ventrally and unites with the Laurer's canal and the oviduct to form the uterus.

The Laurer's canal (21) is rather long and passes from the common meeting point with the oviduct, the median yolk duct and the uterus in a dorso-median direction to the opening in the dorsal body wall (Fig. 3, 38). In the section shown in this figure it is seen to be filled with sperm which protrudes from the opening. The cells constituting the shell gland (37) are grouped together about the Laurer's canal, the median yolk duct, the yolk reservoir and the oviduct between the ovary and the dorsal body wall.

It will be noticed that the complex of organs just described is not 
situated between the anterior testis and the ovary as is the case of the other species of this genus (Looss, 1901), but lie between the ovary and the dorsal body wall, and in case of greatly contracted individuals more or less in front of the ovary (Fig. 2). This is also true of much extended specimens, in which the ovary and the anterior testis are separated by a considerable distance: in these worms also these organs lie dorsal to the ovary.

Looss (1901) has shown that the species of the genus Stephanochasmus fall naturally into several groups which he thinks form sub-genera and may possibly be equivalent to genera. One of these groups is represented by Stephanochasmus cesticillus (Molin) and is distinguished by the greater width of the body behind than in front of the acetabulum, the extremely long cirrus sac and the ventral interruption of the oral spines. In another group, which is represented by S. minutus Looss, the hinder part of the body is also broad, the cirrus sac is relatively short and the oral spines are not interrupted ventrally. In the third group, which is represented by $S$. pristis, the body is not widened posteriorly, the cirrus sac is relatively short, the oral spines are not interrupted ventrally and the genital glands are separated from one another by wide spaces.

S. casus approaches nearest the second of these groups, being more closely allied to $S$. minutus than to any other species. It differs from it in being much larger, in having a relatively very long cirrus sac and in having yolk glands which extend forwards to the acetabulum.

Linton (1910) has described a worm under the name of Lechradena edentula which I believe to be identical with $S$. casus. Its structure is the same in every detail except that it is without spines. Linton found but a single specimen of the species which had probably lost its spines as a result of a slight superficial maceration, a thing which might very easily happen.

\section{REFERENCES.}

Linton, E. (1910). Helminth Fauna of the Dry Tortugas. Ir. Trematodes. Papers from the Marine Biological Laboratory at Tortugas.

Looss, A. (1901). Ueber die Fasciolidengenera Stephanochasmus, Acanthocasmus und einige andere. Centralbl. f. Bakteriol. Parasitenk. u. Infektionskr. 1 Abt. XXIX, pp. 595, 628, 654, et seq.

Sommer, F. (1880). Zur Anatomie des Leberegels, Distomum hepaticum L. Zeitschr. f. wiss. Zool. xxxIv, pp. 539-640, pls. 27-32. 


\section{Explanation of the Figures.}

All the drawings except Figs. 8, 9 and 10 were made with the aid of the camera lucida.

1. Acetabulum. 2. Basal dise of euticular spines. 3. Bulbous base of cuticular spines. 4. Circular muscles. 5. Cirrus. 6. Cirrus sac. 7. Cuticula. 8. Cuticula of cirrus. 9. Cuticula of metraterm. 10. Cuticular bristles. 11. Cuticular spines of cirrus. 12. Cuticular spines of metraterm. 13. Cylindrical rim of cuticular spines. 14. Eggs. 15. Excretory pore. 16. Exeretory vesicle. 17. Fold of prepharynx. 18. Genital pore. 19. Genital sinus. 20. Intestine. 21. Laurer's canal. 22. Longitudinal muscles. 23. Median yolk duct. 24. Metraterm. 25. Oesophagus. 26. Oral spines. 27. Oral sucker. 28. Ovary. 29. Oviduct. 30. Parenchyma cells. 31. Pharynx. 32. Pigment granules. 33. Prepharynx. 34. Prostate cells. 35. Prostate portion of cirrus sac. 36. Ring dise of cuticular spines. 37. Shell glands. 38. Sperm. 39. Subcuticular cells. 40. Testis. 41. Transverse yolk duct. 42. Uterus (egg-forming portion). 43. Uterus (egg storing portion). 44. Vas deferens. 45. Vesicula seminalis. 46. Wall of cirrus sac. 47. Yolk glands. 48. Yolk reservoir.

\section{EXPLANATION OF PLATE XIII.}

Fig. 1. Stephanochasmus casus; dorsal aspect with extended cirrus, $\times 20$.

Fig. 2. The genital-tract; from a contracted specimen, $\times 40$.

Fig. 3. Cross section of a worm through the Laurer's canal, $\times 100$.

Fig. 4. The intestinal epithelium showing a regular arrangement of protoplasmic projections, $\times \mathbf{5 0 0}$.

Fig. 5. Cross section of the genital sinus, $\times 300$.

Fig. 6. Cross section of metraterm (24) and cirrus (5) near their proximal end, $x 300$.

Fig. 7. Cross section of metraterm (24) and cirrus (5) towards their distal end, that of the cirrus being somewhat diagonal, $\times 300$.

Fig. 8. A single spine from the cirrus.

Fig. 9. A single spine from the metraterm.

Fig. 10. Diagram of the genital tract. 
PARASITOLOGY, VOL. VIII. NO. 3
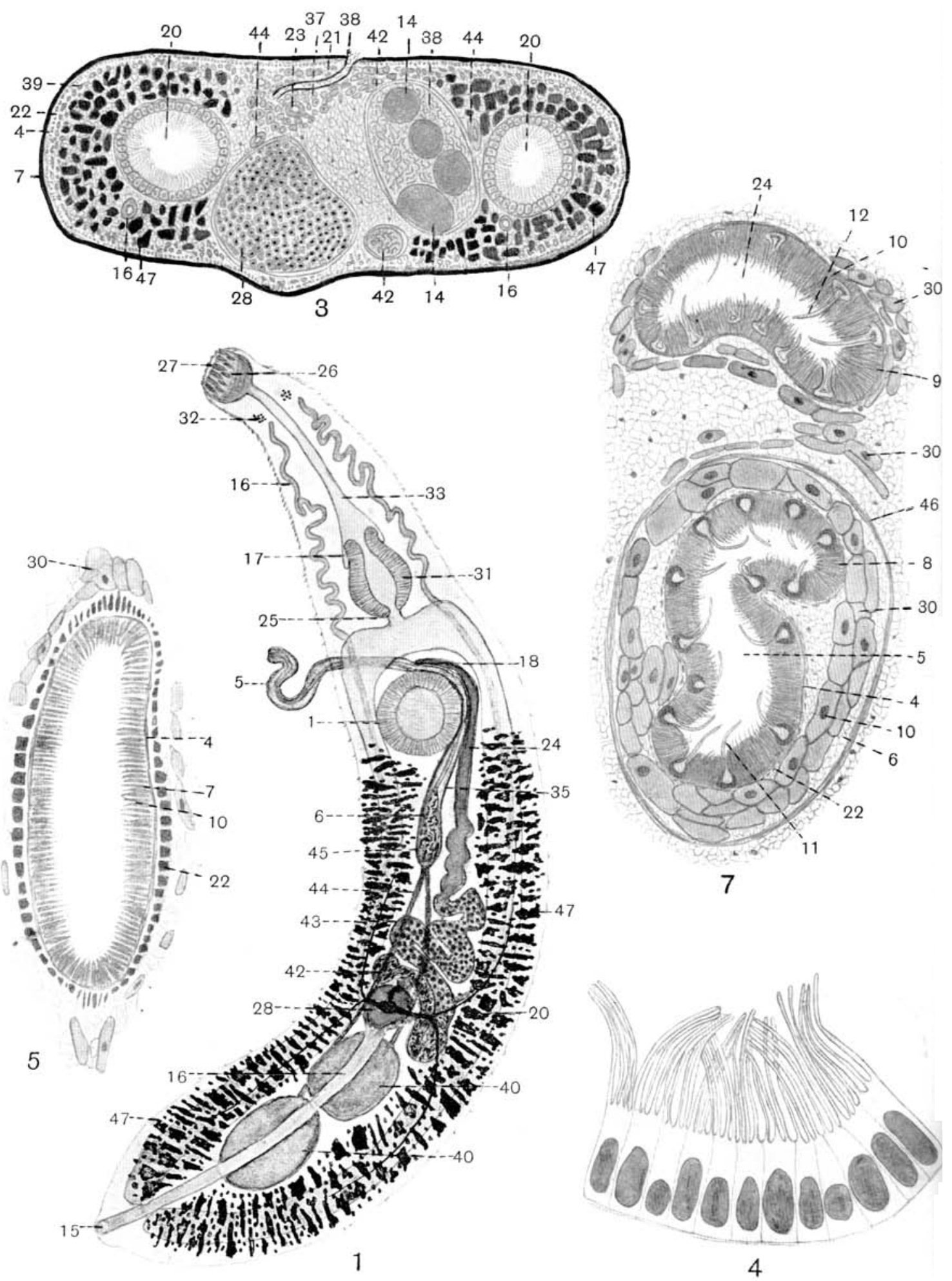

II. S. Pratt, del. 
